\title{
THE BRITISH CONTRIBUTION TO SCIENCE AND TECHNOLOGY IN THE PAST HUNDRED YEARS*
}

\author{
By H.R.H. THE DUKE OF EDINBURGH, K.G., F.R.S. \\ President of the British Association
}

$\mathrm{T}^{\mathrm{o}}$ O mark the opening of this year's meeting, His Majesty The King has been graciously pleased to send the following message :

I shall be glad if you will express to the members of the British Association for the Advancement of Science my appreciation of their having once more honoured a member of my family by inviting him to be their President.

I trust that this year's meeting of the Association will further the development of Science for the benefit of mankind throughout the world, and prove an encouragement to all those men and women who are so devotedly working for that end.

On your behalf I propose to reply in these words :

The Members of the British Association for the Advancement of Science assembled at Edinburgh send Your Majesty their humble duty and their loyal thanks for Your Majesty's Patronage of the Association and your gracious message of encouragement.

I am to assure Your Majesty that the development of Science for the well-being of Your Majesty's Realm and for the general welfare of mankind is the constant object of the Association.

We will strive with all humility and with the grace of God to apply the blessings of scientific and technological improvement to the problems which face us all to-day.

In Aberdeen in 1859 my great-great-grandfather started his address to the British Association with these words :

"Your kind invitation to me to undertake the Office of your President for the ensuing year could not but startle me on its first announcement. The high position which Science occupies, the vast number of distinguished men who labour in her sacred cause, and whose achievements, while spreading innumerable benefits, justly attract the admiration of mankind, contrasted strongly in my mind with the consciousness of my own insignificance in this respect."

I cannot improve on this to express my own feelings; but, like him, I reflected upon your invitation and came to the conclusion that it is just as an outsider, a layman so to speak, that $I$ can be useful to you and to science. This very invitation seems to me to demonstrate that science is not a magic circle and that you wish us to enter your confidence. In return the least $I$ can do is to show our appreciation of the work of scientists and to give you a layman's impression of the march of science in the past hundred years. I crave your indulgence if $I$ have drawn any false conclusions and I hope that during the meetings which will follow this one, the experts will take the opportunity to make any corrections.

* Presidential address delivered at Edinburgh on August 8.
The Prince Consort had very much less reason to be modest about addressing you than I have, because this year we celebrate the anniversary of the Exhibition which was his greatest achievement, and an event which had an untold value to science. Let us hope that this year's Festival will be judged a worthy successor and an inspiration for the future. I am proud to pay tribute to this man who saw so clearly the part science was destined to play in the future of this country, and my address is largely the story of the fulfilment of his hopes.

\section{The Starting Point}

In a review of British science and technology, 1851 is a convenient starting point for two reasons. First, the Exhibition of that year can be regarded as a gigantic stocktaking of the national resources and technical skill; secondly, because it marked the end of the Industrial Revolution and the conversion of Victorian England to the policy of industrial expansion on which our future still depends. The period as a whole saw the climax of our industrial supremacy and its inevitable decline when countries with greater resources and population learned from us the lessons of the mechanization of industry. It also covers the birth and growth of the new concepts of modern science.

Social conditions of a hundred years ago were, generally speaking, the outcome of the Industrial Revolution, but with all the traditions of the Eng. land of agriculture, cottage industry and small market towns. The population of 20 millions was growing fast but still small compared to our 50 millions of to-day. Education was limited to a minority and was almost entirely classical, so the new profession of engineering had to draw its recruits from a different sphere that of self-educated men. A new wealthy class was growing up in the commercial world to rival the old aristocracy. There was unbounded optimism about the future and ample scope in commerce and industry to attract all intelli. gent and enterprising men. The number of poor was on the increase and their conditions were deteriorating because, as yet, no social conscience had grown up to replace the patriarchal responsibility of the landowners and master craftsmen.

In the domestic field, lighting was by candle and oil lamps, cooking and heating by coal or wood in ranges or open fires with the consequent enormous waste of energy. Food had to be fresh or crudely preserved, and thus needed to be produced locally. In health and hygiene the figures speak for them. selves. In 1851 the infant death-rate was 150 per 1,000 live births compared with 25 per 1,000 to-day. Anæsthetics, antiseptic surgery, biochemistry, tropical medicine, were all virtually unknown or in their infancy. Psychology had not yet achieved independence from philosophy on one hand and physiology on the other. 
This was the age of the practical engineer and of processes arrived at by intuition born of experience and by trial and error. Technology was concerned with the application of steam-power, with metallurgy and the working of metals for various purposes, and with the production of machine tools and precision machinery. Men were already turning their minds to other types of engines, and the internal combustion engine was in the process of development.

Scientists, while contiruing their search for the secrets of Nature, were beginning to turn their attention to exploring the empirical developments of industry. Their numbers as yet were small, the endowments for research were negligible and much of their work was carried out in the watertight compartments of the different sciences. But the seed had been sown, and it was not long before scientists and engineers were preparing the way for the great technological harvest of the twentieth century.

\section{The Conditions}

The changes brought about in the lives of men and women in the last hundred years have been greater and more rapid than during any other period in history, and these changes have been almost entirely due to the work of scientists and technologists all over the world. They have not only affected the way of living of all civilized peoples but have also vastly increased our knowledge about ourselves, the earth we live on and the universe around us. I cannot emphasize too much that the sum total of scientific knowledge and technological progress is an international achievement to which every civilized country has made some contribution.

Now before considering the contribution of the British Commonwealth, I should like to sketch what appears to a layman like myself to have been the main influences on the course of scientific and tech. nical achievements since 1851 and their relation to one another.

The great stimulus of the 1851 Exhibition created a growing interest in technical education and research, followed by a widening of the scientific horizon which was soon to find expression in borderline subjects. For the next fifty years science advanced rapidly; but in most fields there was a wide gap between science and industry. Electricity was an exception, and the groundwork was already being laid for the electrical revolution of the Victorian age. Medicine was on the verge of breaking away from medieval practice and taking the first steps towards its modern pattern, while British colonial development stimulated the study of tropical disease.

Between 1851 and 1870 , practice, in many indus tries, was ahead of science, and in that period the large number of inventions of the Industrial Revolution were progressively improved and widely applied. These inventions, which added so much to our industrial production, were mainly the work of British genius. They were of great economic advantage to this country and were quickly exploited commercially. New factories and plants were built to include the very latest ideas, and with the expansion of industry came the demand for more and more new ideas and greater efficiency. This demand was a direct stimulus to technological invention as well as an indirect stimulus to science. We are still struggling with the social results of this vast expansion.
From 1870 to 1890 the highwater mark of British industrial expansion, as compared with other countries, had been reached and the competition of the United States and Europe was just beginning to be felt. But the lack of serious competition hitherto had bred a feeling of over-confidence and satisfaction in the methods and processes employed. The result was a conservative attitude towards technical change and, particularly in the older industries, neglect of scientific research. Accumulation of wealth and the income from foreign investments in any event made the country as a whole less dependent on the efficiency of her industries. Concurrently a subtle change occurred in the type of British exports. So far the products of our machinery, such as rails and rolling stock, had been shipped abroad for immediate use; but now machines themselves were exported to do their work in the factories of Europe and America instead of in Britain. The result of this was to intensify foreign industrial competition between 1890 and 1914 ; but with the increasing demands from the Colonies the volume of British exports was not greatly affected.

Then came the critical years of the First World War, bringing a realization of the part science must play in the industrial and military strength of the nation. For the first time in history a real attempt was made to enlist the services of science in the war effort, and the Department of Scientific and Industrial Research was founded to further the application of science in industry through Government laboratories and through research associations.

The effects of these measures appeared clearly in the inter-war years, when there was a marked swing of education from classics towards science. Coupled with this, the War had directed the attention of many research scientists to practical objectives, so that after the War there was a rapid expansion of indus. trial research. Scientific progress was no longer confined to the work of a few brilliant individuals, but came also from teams of research scientists each working on different parts of the same problem. It was during this period that many new commercial research laboratories grew up, employing scientists to discover new processes and materials connectad with their industry as a direct weapon of competition.

The War had also shown a great weakness in our dependence on foreign production for many vital articles, such as dyestuffs, scientific instruments and optical glass, in the manufacture of which scientific research played an essential part. This weakness was remedied with the help of the Key Industry Import duties, which gave the necessary support and encouragement to the establishment of these industries at home.

It is true that manufacturers in some of the older industries still clung to traditional methods in spite of the pressure of competition from America and other countries. In this connexion it is significant that the history of production engineering after 1890 is almost entirely confined to the United States.

It was, however, a period of rapid development in Britain. The invention of the internal combustion engine and the pneumatic tyre had opened new branches of industrial engineering, and the demand for fuel for motor-cars and aircraft gave birth to the new technology of oil. In the electrical, chemical and aircraft industries, science was fully enlisted in the fields of electronics, synthetic fibres, plastics, aerodynamics and light alloys. Consequently the outbreak of war in 1939 found us in a much stronger position 
to meet the immense demands it made on all branches of technology for new gadgets, machines and weapons. From the outset science in all its forms and branches was harnessed and completely co-ordinated with the war effort. It was only the intimate partnership of science and engineering with the staffs of the Fighting Services that enabled us to meet swiftly and effectively the ever-changing menace of total war.

The tremendous demands on our industries had some good after-effects. Once again these demands revealed weaknesses where our industrial capacity was out of date. The realization of this has initiated comprehensive reconstruction on most modern lines. The almost complete absence of income from our foreign investments has forced us to rely once more on our capacity to make the goods the world requires. Our industry and productivity have shown a wonderful improvement; but there is still a lot more that can be done. The rate at which scientific knowledge is being applied in many industries is too small and too slow. Our physical resources have dwindled; but the intellectual capacity of our scientists and engineers is as great as ever, and it is upon their ingenuity that our future prosperity largely depends.

\section{The Contribution}

I would now like to make a brief survey of the British contribution to natural knowledge and technology and pay a tribute to some of the great men of science of the past hundred years.

In some branches almost the whole story can be told, since one problem after another has been solved by British scientists. In others there are many blanks and gaps where the vital links in the chain were forged abroad. But looking at the whole vast fieldx of abstract and practical science there can be no doubt that during this period the contribution of the British Commonwealth has been of outstanding importance.

Our knowledge of the stars, the heavens, and our place in the universe has increased steadily through the centuries; but since 1851 some of the most important links were supplied by such men as Eddington, Jeans and Milne in their work on mass, luminosity and stellar evolution. Huggins made a great contribution with his application of spectrum analysis to astronomy, and Lockyer's discovery of helium in the sun had a significance far beyond the realms of astrophysics.

Coming nearer to the earth, the work of Abercromby and Shaw on the behaviour of the earth's atmosphere in the troposphere started the scientific study of weather and weather prediction, and Appleton's research into the ionosphere extended this to the upper air.

Chemistry has fascinated man from the earliest times, and vast progress has been made in the past hundred years both in knowledge and theory. Much fresh ground was broken by Crookes by his work on spectra, his discovery of thallium and of 'radiant matter' known later as cathode rays. Long after everyone was quite sure of the composition of the air, Rayleigh found another ingredient which he called argon and so started the hunt for other inert gases. In organic chemistry both Perkin and Robinson have added enormously to our knowledge of the structure of carbon compounds, and to our power to copy natural products synthetically. The development of X-ray analysis by the two Braggs, father and son, has given us a means of finding the actual arrangement of the atoms in the molecule and has revealed the accuracy of the chemists' conclusions about the architecture of molecules based on their reactions with one another. This is a most striking example of the power of the theoretical and practical scientist to penetrate Nature's secrets.

Going beyond the chemist and his molecules, we come to the physicist and the study of even smaller particles. Thomson's discovery of the nature of the electron was the first attack upon the integrity of the atom. Next, thanks to Rutherford's brilliant research and keen intuition, came the nuclear theory which revolutionized our ideas of matter. To prove it, he was the first man to succeed in the transmutation of an element. It is appropriate to mention Moseley's work on the X-ray spectra of the elements, as it already showed such great promise, before he was killed at Gallipoli.

Parallel with this activity in the physical sciences there occurred a technological revolution of even greater scope and variety. The Darbys of Coalbrookdale were the lineal ancestors of Bessemer, Thomas and Siemens, and the whole technology of metals. First, cheap cast iron followed by cheap steel, then steel from phosphatic ores, completely changed the materials available to engineers, shipbuilders and architects. Scientific metallurgy can be said to have started when Sorby first applied a microscope to the surface of metals. The way was opened for the investigation of the metallic alloys which came in quick succession from developments in which Hadfield and Rosenhain made outstanding contributions.

It was not long before the possibilities of these new materials were recognized, and the great majority of the mechanical developments of the period were due to new alloys which could withstand higher stresses. But before these materials could be fully used, Maudsley and Whitworth had to lay the foundations of production engineering, and Mushet had to do pioneer work in developing tungsten steel as the first high-speed cutting tool.

The reciprocating steam engine of the Industrial Revolution was the main source of power until Parsons invented the steam turbine, which revolutionized large-scale power production on land-and sea. But that was not the only source of power to rival the push-and-pull engine. The internal combustion engine, in which Dugald Clerk and Akroyd Stuart were among the early pioneers, has proved to be a formidable challenger in many fields. In marine engineering, Froude's work on hull forms and propellers enabled the full benefit of the new prime movers to be reaped at sea.

Here I wish I could mention early British pioneers of motor-vehicles; but, as is well known, restrictive legislation drove the development of the motor-car abroad, until the repeal of the speed limit in 1903 gave scope to the genius of Royce, Lanchester and Ricardo. In place of the motor-car, however, we have Lawson to thank for the invention of the safety bicycle; and all wheeled vehicles except those running on rails owe their rapid development to Dunlop's invention of the pneumatic tyre. The material required for this started the vast natural and synthetic rubber industry, and has made famous the name of Wickham for a brilliant feat of smuggling, when he brought the rubber seeds from Brazil to Kew, from which sprang the rubber plantation industry of the East.

In flying, the names of the pioneers and their feats are legion, and more than in any other mechanical 
science the development of aerodynamics has been shared by many nations; but Lanchester's vortex theory was one of the stepping stones to powered flight, and the achievement of Alcock and Brown in making the first Atlantic flight in 1919 speaks highly for the tremendous scientific and technological background of flying in Great Britain. Of outstanding importance and consequence was the genius. which Mitchell brought to aircraft design, and, more recently, Whittle's pioneer work has given us the lead in jet engine production both for civil and military use.

Following on the immense progress in metallurgy and mechanical engineering, the most far-reaching development of the period has been that of electricity and electronics. Although the key discovery belongs to Faraday in an earlier period, the second founder of the science is undoubtedly Clerk Maxwell, with his classic treatise on electro-magnetism. The use of electricity for domestic and industrial purposes was helped by Wilde's development of the dynamo and then by Swan's incandescent lamps. Wheatstone and Kelvin pioneered the use of electricity for communication by their work on line and cable telegraphy. Wireless telegraphy soon followed, and the work on tuned circuits by Lodge, and Marconi's many brilliant developments made in Britain with the General Post Office and the Navy, soon made radio a practical proposition. Heaviside and Appleton made further contributions on the propagation of radio waves. It is interesting to see that the technique used by Appleton in his pulse-ranging on the ionosphere and upper layers was later developed by Watson-Watt into radar, which is now almost indispensable to airmen and seamen all over the world. Here Randall's development of the magnetron for high-frequency radar was one of the major contributions to the Allies' equipment for war.

Television has a wide parentage, but Baird's name will always be linked with the first successful pictures.

Another great innovation of this hundred years was the discovery and development of plastic and synthetic materials. The story starts with Parke's discovery of celluloid and Cross and Bevan's manufacture of viscose which gave birth to the rayon industry and the many later types of synthetic fibre. Perkin's mauve, first of the aniline dyes, and Kipping's new silicon compounds were, however, disregarded by industry in Great Britain. But we see to-day a change of heart in the development in our industrial laboratories of two new plastics, 'Perspex' and polythene, with almost an unlimited range of applications in the air, on the ground, and at sea.

The effect all this has had upon the citizen varies naturally with where and how he lives; but basically it has given him reliable light and heat in his home, push-button communication with almost any part of the world and home entertainment of a high quality. His transport on land, at sea, and in the air is quick, comfortable and clean. In addition, he has a vast range of materials with which to clothe himself and to furnish and embellish his home. Almost more important, these developments have brought about a complete change in his conditions of work.

But if the citizen has benefited, so too has science from the great array of new techniques that have been invented and the new tools with which the scientist and technologist can burrow, hack and worry at the growing mountain of problems to be solved.
So far I have dealt with the physical sciences. Now I would like to turn briefly to the biological and psychological sides, which after a slow beginning in Great Britain have made increasingly rapid progress.

The whole field of biological science in this period is overshadowed by the works of Darwin presented in his "Origin of Species" and "The Descent of Man". Nothing has done so much to widen man's thoughts as his conception of evolution as the great law controlling living things, "that progress comes from unceasing competition, through increasing selection and rejection".

Tn the basic study of living things some of the most important contributions from Britain were the pioneer work of Francis Galton and William Bateson in the field of heredity, Sherrington's work on the integrative action of the nervous system, and Dale's and Adrian's contributions to our knowledge of the transmission of nervous impulses.

The science of biochemistry is relatively new and Gowland Hopkins was its founder in Britain. His discovery of the significance of accessory food factors, leading up to the recognition of vitamins, started the modern science of nutrition. Other landmarks were Bayliss and Starling's recognition of the part played by hormones in the blood stream, followed by Banting and Best's isolation of insulin, and Harington's synthesis of thyroxin in Edinburgh.

Fleming, working on mould cultures, discovered the antibacterial properties of penicillin, and later Florey and Chain, at Oxford, found that penicillin could be extracted in a highly purified form, and used it to treat human disease.

Modern surgery can be said to have been born in Scotland with Simpson's discovery of the use of chloroform as an anæsthetic and Lister's antiseptic technique based on Pasteur's bacteriological discoveries. A further advance of the greatest value to surgery as a science was Macewen's aseptic technique, which made surgery clean and safe, followed by his classic work on the brain and spinal cord.

If Lister was the father of modern surgery, then Manson was the father of tropical medicine, and it is particularly in this field that the British contribution has led the world. The discovery by Ross that malaria is carried by the anopheles mosquito and, much later, the work of Fairley in Australia on its prevention and cure, have been of the greatest benefit to mankind. Bruce will always be remem. bered for his discovery of the part played by the deadly tsetse fly in the transmission of sleeping sickness and his work on Malta fever. Finlay, Adrian Stokes and Hindle stand high among the names linked with the study and prevention of yellow fever.

These were all vital efforts towards the prevention of sickness; ; but there is another aspect of medical practice in which the Commonwealth has taken a leading part the promotion of health. It was Sir John Simon, the first medical officer appointed to a central authority, who made a careful statistical study of the causes of sickness, with the view of taking effective measures for the health of the community at large. Through his leadership, health services have been provided in regular stages throughout the country. At first these were largely aimed at providing pure water, effective sanitation, and the abolition of slums; but since the beginning of the present century the personal health services, especially in the case of mothers, babies, and school children, have become national in scope and lead the 
There are two other fields in which the biological sciences play a major part. The first is in the preservation of food and in nutrition, which has had the most profound economic and social effects. The ability through freezing, drying and canning to import large quantities of food has enabled a rapidly increasing population to maintain and increase its standards of living, which would have been impossible had it been dependent on British agriculture alone. The scientific study of nutrition has made it possible to improve the health of the population and in war to feed the people with the minimum of waste.

Mort had the first freezing works in the world at Sydney, and was a pioneer in refrigeration; but success in transporting meat to Britain had to wait for the development of more reliable refrigerating plant. Since 1918 the Food Investigation Laboratories of the Department of Scientific and Industrial Research, of which Sir William Hardy was the first director, have established the basic biological knowledge on which the storage and transport of meat, fish and fruit are now largely based.

The second field is in agriculture, where in order to compete with cheap foreign foods the most success. ful farmer is one who enlists the full assistance of science. Lawes, who discovered how to make and use superphosphate, and started the great fertilizer industry, was quick to realize this. He founded Rothamsted, now the oldest agricultural research station in the world, and there he and Gilbert carried out the first scientifically controlled field experiments which laid the foundation of agricultural science. Later, Biffen's pioneer work in plant breeding at Cambridge became one of the greatest contributions to the problem of feeding the world's growing population. $\mathrm{He}$ showed how it was possible to breed strains of wheat combining resistance to disease with high yields and good milling properties. In the field of animal breeding, the foundation of the most important aspect of British agriculture to-day, I will mention among the many investigators only Cossar Ewart and Crew, who did so much to advance its scientific study here in Edinburgh. The mechanization which was to revolutionize farming in all parts of the world was also under way and Britain was playing a leading part. The reaping machine, for example, was invented by Patrick Bell in 1826 although it was not manufactured until 1853 .

There is no need to point out the effect which all these improvements, discoveries and inventions have had on society. It is this group of biological sciences which have had the most far-reaching social results, and it is particularly during and since the Second World War that it has been possible to exploit them.

There is one science which I have not yet mentioned. It is both the youngest science and the oldest problem. The study of man's mind was the province of the philosopher until the middle of the nineteenth century, when it separated from him and began its independent existence as the science of psychology. The foundations were not laid in Great Britain: but important contributions were made, both from the biological and the philosophical sides, by men like Ferrier, Bain and Ward. Sully's work on child psychology was the first of its kind. But probably the most outstanding figure in this country was Galton, whose teaching is widely respected in all psychological laboratories, and who was the first to develop an interest in the mental differences between individuals - a field in which British psychology has made some of its greatest contributions. Again, it is only recently that full practical advantage is being taken of the progress made in this branch of science; but the results of that application may be as important as the many more easily understood developments in the purely physical world.

\section{The Implications}

The story of the British contribution to science in the past century is indeed impressive, and I am very pleased to have this opportunity of paying tribute to the men whose achievements I have been discussing. But this story would not be complete without studying the wider implications of their work and examining some of the lessons to be learnt from it.

The concrete measurement and indirect effect of all scientific effort is the general improvement in the conditions in which people live and work; it is in the improvement in health, in the expectation of life and standards of living; the latter including not only food and clothing, but also housing, home comforts, medical care, education, books and newspapers, recreations and travel facilities. In every one of these directions the progress that has been made has amounted to a revolution.

Not all this springs directly from science and invention. Much has been due to the politicians and administrators, and behind them to religion, morals, education, art and the complex influences which we call culture. But even there science has stood beside the authors of progress to advise, to help and sometimes to guide.

Now as science and technology are so vital to the future strength and prosperity of the British Commonwealth, the great problem is to discover the conditions under which they are most likely to flourish. The records show that both depend very much on co-operation, and upon the linking up of a long chain of discoveries, one with another; so that it is quite exceptional for the credit of a great advance to belong to one man or even to one country, although it will always require the flash of inspiration to weld the links into the chain. To-day the development of team-work in laboratories has made this truer than ever. For many reasons, but principally because of the increasing complexity of research and its cost, such team-work is becoming more and more the rule. We need not repine at this; but it would be a disaster if the individual inquirer working in his own laboratory were discouraged out of existence.

While the quality of scientific work is determined by the quality of the scientist, the quantity of scientific output is determined by the money avail. able. The rapid progress of science in Britain has owed much to the growing support and sympathy of government and individual benefactors and to the endowment of research by industrial corporations. However, the basic discoveries that mark the great advances depend on the accident of individual genius and are not at our command.

The scope and intensity of the progress of applied science and technology, on the other hand, bear a close relationship to the circumstances of the time. Technology, as the combination of scientific knowledge with the practical ability of the inventor to apply that knowledge to the solution of particular problems, comes into play with any new discovery of scientific fact. The latest particle of truth is then developed, according to the circumstances of the time, for military, commercial or medico-social purposes. It is a sad reflexion that the urgent demands 
of modern war can produce advances that might otherwise take many years to develop, especially in the costly and uncertain experimental stages.

The rivalry between large commercial undertakings, using science to improve their products or processes as a direct means of competition, has produced a steady flow of improvements and develop. ments. However, the fruits of this form of scientific work are sometimes open to considerable misuse. The discoveries of these commercial laboratories may be kept secret, and in some cases a number of teams may be working on the same problem, which may have already been solved elsewhere. The buying up and suppression of patents and discoveries to protect equipment from becoming obsolete has also been known to happen. I am glad to see, however, a change of outlook in the growing quantity of pub. lication of the results of industrial research.

It would seem that science has become so well established that nothing can stand in the way of its natural growth. This is far from the truth. Since the earliest times the natural conservatism of laymen has acted as a powerful brake to the adoption of new ideas which do not rigidly conform to his notion of the correct order of things. In its most violent form it will produce unreasoning anger, utter disbelief in face of the clearest evidence or provoke plain ordinary laughter. The storm raised by Darwin's "Origin of Species" is an excellent example where even scientists failed to keep an open mind.

The position seems better to-day, and I am sure that Sir Harold Hartley, our immediate past president, spoke for all scientists when he said : "To-day, with our greater understanding, there is humility in the minds of all scientists. The further we penetrate into Nature's secrets the more clearly we see the ever-receding frontiers of knowledge."

The resistance towards anything new or unexpected is balanced, on the other hand, by bursts of enthusiasm that some particular discovery or invention will see the end of all our troubles. The belief in the philosopher's stone seems to be just as great as ever.

As the front of pure science has advanced, so its lines of communication to practical exploitation have got longer and longer. The time was when the whole process of discovery, application and exploitation could be achieved by one man. In our time a great army of scientists, technicians, inventors, designers and production engineers is required to keep the lines of communication open. Quite how important some of the members of this follow-up team have become is not always appreciated. In his presidential address in 1948 Sir Henry Tizard emphasized this point when he said : "All depends on good design and production. Our weakness in the war was not to be found in what was best to do, nor in the scientific work of how to do it. It was when the stage of design and production was reached that we fell short of the best standards."

This was true already when Whitworth invented the screw micrometer, which was afterwards put into production in Germany and the United States, and up to the First World War all micrometers had to be imported into Britain.

To Prof. Kipping of Nottingham goes the credit for the basic work which led to the development of silicones in Russia and the United States, and yet until this year we have been dependent on imports from the latter of marketable silicone products.

There are many cases in the Navy where a piece of apparatus has been used operationally exactly as the inventor put it together, with all the resulting disadvantages in maintenance and efficient operation. The limitation in performance, except in some cases, is practical as opposed to scientific. Where the basic scientific principles are known by all nations the advantage lies in the good design of equipment for practical use.

A more general and far-reaching matter for concern, and possibly the most vital factor affecting the industrial application of scientific research, is the lack of a co-ordinated system of scientific and technological education in Britain. Excellent as they are, the existing institutions, which have grown up to meet particular circumstances, do not produce anything like enough trained technologists to meet the urgent needs of scientific development in industry and to provide leaders for the future. It is to be hoped that the new and rather uncertain science of educa tion will develop sufficiently quickly to point the way to a speedy solution of this problem.

The shortage in Britain of "personnel trained and eager to apply scientific knowledge and scientific methods to practical ends"- as Sir Ewart Smith said last year-is only one of the many shortages which the world is now facing. Among them are food, nonferrous metals, steel alloy metals and sulphur. These very shortages are due to the scientific complexity of present.day life, and it is only by science that they can be overcome. Naturally, there are many ways of tackling this problem; but the most obvious are : first, by improved design to secure economy in production and the minimum use of scarce materials ; secondly, by the development of substitutes made from raw materials which are still abundant ; thirdly, by the reclamation of scrap and improved methods of using low.grade ores ; finally, the development of renewable raw materials such as timber to satisfy the world demand for cellulose. Some of these shortages are partly due to the huge inevitable waste of war and its consequences, and partly to the lack of any comprehensive survey of the world's resources and requirements. It is only by an accurate knowledge of the world's resources that we can foresee the scope and magnitude of the future problems which science and technology have to meet and which only they can solve.

It is, therefore, good news that the Economic and Social Council of the United Nations has resolved "to promote the systematic survey and inventory" of those resources which are not already covered by the Food and Agriculture Organization.

We have evolved a civilization based on the material benefits which science and technology can provide. The present shortages are a timely reminder of the slender material foundation on which our civilization rests, and of our dependence upon science and technology.

\section{The Conclusion}

The pursuit of truth in itself cannot produce anything evil. It is in the later stage when the facts dug up enter the process of application that the choice between the beneficent and destructive development has to be made. It is quite certain that it is an exception if any particular discovery cannot be used equally well for good and evil purposes. Happily the beneficent exploitation of scientific knowledge has kept pace with its destructive application.

In a mid century article The Times put it this way : ". . . It has been an age of great achievement. The lines of progress in which the Victorians trusted 
have been pursued farther and faster than they foresaw. Scientific discovery, from which above all their doctrines of progress derived, has swept forward on an enormous front. The conquest of the air has made possible an intercourse and understanding between distant peoples such as our ancestors could not imagine - and it has been diverted to the vast destruction of men and cities. The invention of wireless telephony has opened a channel through which liberating truths might be proclaimed to all the listening earth-and every would-be despot has used it to suborn the blind masses into the worship of false gods. The medical art has performed miracles; the cures of immemorial pestilences have been found, infancy has been safeguarded and old age tended, so that the normal expectation of life has been extended by years - aside from the new and universal apprehension of sudden death."

To my mind it is vital that the two sides of scientific development are fully and clearly understood, not only by the research scientist, inventor, designer and the whole scientific team, but also by all laymen. The instrument of scientific knowledge in our hands is growing more powerful every day; indeed, it has reached a point when we can either set the world free from drudgery, fear, hunger and pestilence or obliterate life itself.

Progress in almost every form of human activity depends upon the continued efforts of scientists. The nation's wealth and prosperity are governed by the rapid application of science to its industries and commerce. The nation's workers depend upon science for the maintenance and improvement in their standards of health, housing and food. Finally, superiority or even our ability to survive in war is a direct measure of the excellence and capacity of the scientific team.

This team of research workers and engineers has a dual responsibility, one for its work and the other as informed citizens, and it can only fulfil its proper functions if its members have a sound general education as well as a thorough training in science. It is no less important that the people who control the scientific machine, both laymen and scientists, should have a proper understanding and appreciation of what science has grown into and its place among the great forces of the world.

It is clearly our duty as citizens to see that science is used for the benefit of mankind. For, of what use is science if man does not survive?

\section{SUMMARIES OF ADDRESSES OF PRESIDENTS OF SECTIONS}

\section{A HUNDRED YEARS OF METEOROLOGY}

T his presidential address to Section A (Mathe1 matics and Physics) Sir David Brunt outlines the development of meteorology during the past hundred years. Before dealing with his main theme, he points out that the Greek philosophers Aristotle and Theophrastus had developed meteorology in the fourth century B.c. so far that their ideas dominated the meteorological thought of Europe for nearly two thousand years, while Pindar set up a standard of forecasting which even to-day is difficult of attainment, except on rare occasions.

The re-awakening of independent thought took place about the time of the foundation of the Royal Society in 1660, and the influence of that Society remained very great up to the time when control of official meteorology in Great Britain passed into the hands of the Air Ministry in 1920.

Many workers with creative minds have, of course, been indispensable on the research side of meteorology, and the names which Sir David mentions include those of astronomers such as Halley and Laplace, and physicists such as Lavoisier, Wheatstone and Glazebrook. Of particular importance was Sir Napier Shaw, the more so because Shaw was instru. mental in adding the names of those most prominent in Great Britain during the past sixty years, for example, W. H. Dines, C. J. P. Cave, E. Gold and G. I. Taylor. Shaw's services should be judged against the background of the Meteorological Office, to which he went as director in 1905. Shaw found a 'Slough of Despond', into which he contrived to instil some of his own enthusiasm. Shaw made the greatest written contribution to meteorology of the century when he published, in 1906, the memoir entitled "The Life History of Surface Air Currents", a work in which he was assisted by R. G. K. Lempfert. This anticipated the paper entitled "Life Cycle of Cyclones and the Polar Front Theory of Atmospheric Circulation", by J. Bjerknes and H. Solberg, which has laid the foundations of the method of forecasting weather which has been developed during and since the Second World War.

Turning then to the research work now being done in Great Britain as part of a revived scheme of international co-operation, Sir David points out that the problems receiving increased attention include: (a) the nature of the depression of middle latitudes; (b) effects of atmospheric radiation and absorption on the heat balance of the atmosphere; and $(c)$ formation of cloud, rain, ice-crystals and snow. Items $(b)$ and $(c)$ have given the most positive results; as regards $(a)$ we cannot predict where the next depression will form, or even explain the precise conditions which led to the formation of yesterday's depression. In the case of $(b)$ the approximate balance of radiation and absorption in the atmosphere can now be evaluated by graphical methods due to Elsasser in the United States and Robinson in Britain. In the case of (c) we now nearly understand the condensation of ice, and also the artificial production of precipitation. Another new matter which is being investigated has come to the fore as a result of further advances in aircraft design, making flights possible at very high altitudes. These have revealed a new phenomenon called the "jet stream'. This is a stream of air, at lovels between $15,000 \mathrm{ft}$. and $40,000 \mathrm{ft}$., moving roughly eastwards at speeds of 130 knots or more, and traceable for great distances downwind, but sharply restricted vertically and transversely. 